populärer werdenden Einrichtungen. Dabei werden stets nur Notlage und Bedürfnis der Mutter berücksichtigt, nicht aber Bedürfnis und Recht des Kindes. Während in anderen Situationen (heterologe Insemination, Zwangsadoption) das Recht jedes Kindes, seine Abstammung zu kennen, öffentlich und gesetzlich gefordert wird, soll dies bei in «Babyfenstern» ausgesetzten Kindern nicht gelten. Es stehen genügend Hilfsmöglichkeiten für schwangere Frauen in Not zur Verfügung, «Babyfenster» sind ethisch fragwürdig und meines Erachtens nicht zu fördern.

Dr. med. Walter Felix Jungi, Wittenbach

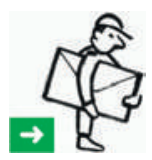

\section{Falsche Frage}

Die Alternative zum Babyfenster hiesse gemäss Herrn Martin Freigabe zur Adoption
[1]. Die Babyfenster sind aber aus der Bewegung der Abtreibungsgegner entstanden und sind aus meiner Sicht auch eine echte Alternative zu Abtreibung. Keine Mutter tut diese Schritte leicht, und niemand findet Babyfenster oder Abtreibung eine tolle Sache. Aber ich bin der festen Überzeugung, dass so einigen humanen Zellen mit diploidem Chromosomensatz es so doch ermöglicht wurde, zu einem Menschen heranzureifen. Niemand sieht in Babyfenstern ein Zeichen liberalen Fortschritts, wie von Herrn Martin erwähnt.

Wie steht es um das Recht des Kindes auf Wissen um seine Abstammung? Ich kenne diese Problematik sehr wohl, stamme ich doch aus einer Familie, in der man, um den Ruf der Familie zu wahren, die Mutter des unehelichen Kindes zwang, das Kind zur Adoption freizugeben. Ein Recht hat eigentlich nur einen Sinn, wenn es auch durchgeführt werden kann. Weiss man doch aus der Transplantationsmedizin, dass die Konstellation nicht so selten ist, dass der vermeintliche Er- zeuger des Erkrankten nicht der richtige Vater sein kann, was wohlweislich unter Verschluss gehalten wird. Die Argumentation mit Recht auf Kenntnis seiner Abstammung führt ad absurdum, weil die Realität komplexer ist und die Umsetzung in gewissen Fällen entweder nicht möglich oder auch gar nicht so hilfreich ist.

Am schwächsten finde ich die Argumentation der Gefahr des Drucks auf die junge Mutter. Hier kann ich einfach nur noch zynisch werden und sagen: Wie sieht es denn da aus, wenn sich jemand entschliesst, aktive Sterbehilfe zu beanspruchen oder sich für eine Abtreibung entscheidet? Es ist doch heuchlerisch, ein solches Argument hier einzubringen, aber den Einfluss der Umwelt in anderen ethischen Fragen zu ignorieren. Interessant. Wie sieht denn Ihr Weltbild aus, Herr Martin?

Dr. med. Markus Karl Stockmeyer, Basel 